\title{
The History of the Southern African Association for Institutional Research
}

Yuraisha Chetty, David Bleazard, Rajan Naicker and Herman Visser

\section{Introduction and Context}

History is important because it teaches us about the past. And by learning about the past you come to understand the present, so that you may make educated decisions about the future.

Richelle Mead

This quotation, by fantasy author Richelle Mead, encapsulates a common understanding of the role of history and its importance. It is likely to resonate strongly with many individuals and organisations who are seeking to understand their history. In an article in the Harvard Business Review, Seaman \& Smith (2012:1) draw attention to a contrasting view, foregrounding the importance of the future, which asserts that, "There is no need to dwell on the past; what matters is the future." Writing in their capacity as business historians, they note that executives often put this view forward. This assertion by business executives appears to be dismissive of history and its role, with more value placed on the future. Seaman \& Smith (2012:1) see the value of history in its capacity to help leaders inspire people towards working collectively and argue that leaders who are impatient with history are missing the important truth that a "sophisticated understanding of the past is one of the most powerful tools we have for shaping the future".

These views of the history of businesses or enterprises can also be applied to organisations in other sectors like the Southern African Association for Institutional Research (SAAIR). According to its constitution, its purpose is to advance institutional research, thereby contributing to the improved operation of higher education institutions in Southern Africa (SAAIR 1994:1). As part of achieving this mandate the SAAIR would need to reflect continually on its history to shape its future.

Within the South African context, higher education legislation and policy documents have referred strongly to the country's past history in articulating the need for the transformation of the Higher Education sector following the demise of the oppressive Apartheid system of government (Badat 2010). These include, among others, the Higher Education Act 101 of 1997 (Republic of South Africa 1997), Education White Paper 3 - A Programme for the Transformation of Higher Education (Republic of South Africa 1997a), the National Plan for Higher Education (Ministry of Education 2001), the National Development Plan 2030 (National Planning Commission 2011) and the more recent White Paper on Post-Secondary Education and Training (Department of Higher Education and Training 2013). The history of 
South Africa has therefore fundamentally shaped higher education discourse and led to the crucial changes that followed, thus lending further importance to the value of knowing and understanding history.

These policy documents have influenced institutional research practice within South African universities. Institutional research practitioners have, for example, to adopt a transformation lens in analysing and reporting student data on graduation and success rates or on enrolment figures. Various developments and research conducted in other Southern African countries also provide important historical points of reflection for institutional research practice in the region. These include, among other initiatives, the Quality Assurance System for Higher Education in Namibia (National Council for Higher Education 2009), The Quest for Coordination of the Higher Education System in Namibia (National Council for Higher Education 2010) containing research into the coordination of higher education in Namibia, the 2010-2012/2016 Strategic Plan of the Tertiary Education Council in Botswana (TEC 2010) and the comprehensive profiling research on Southern African higher education commissioned by the Southern African Regional Universities Association (SARUA) which was undertaken by Kotecha, Wilson-Strydom \& Fongwa (2012). See Chapter 10, which deals with external reporting, for further examples.

The description of the value of the study of history by Seaman \& Smith (2012:3) as offering "pragmatic insights, valid generalisations and meaningful perspectives" is useful and resonates well within the context of historical research on the SAAIR. This chapter on the history of the SAAIR has provided insights and meaningful perspectives through desktop research and document analysis, and through primary research in the form of a survey.

It is important for institutional research professionals, to keep abreast of developments in the profession and to contribute to the body of knowledge about the profession. In this regard, it is important in the Southern African regional context to understand where the SAAIR as an organisation has come from since its inception in 1994. Understanding the history of SAAIR paves the way for guiding it towards envisioning its future.

The founding organisation for institutional research in the USA (AIR), which has existed for just over 50 years, has made important strides in documenting its history, most notably through publications by Rice et al. (2011) and Reichard (2012). Another valuable publication documenting the role, function and contribution of institutional research in supporting the development and transformation of higher education is that by Calderon \& Webber (2015).

Reichard notes a study in the USA dating back to 1701, the year in which Yale was founded (Reichard 2012:4), which could be seen as an early example of "institutional research". However, the "formal" emergence of institutional research through the AIR began with the establishment of the National Institutional Research Forum, which held five annual forums between 1961 and 1965. It was succeeded by the AIR at the sixth forum in Boston in May 1966 (Reichard 2012:8-9). The AIR histories have lent impetus to focussed research in the Southern African context documenting the history and evolution of the SAAIR over the first 23 years of its existence (1994-2016). 


\section{Focus of the Study}

This historical study is limited to the Southern African context, with a particular focus on the SAAIR. The findings are therefore mainly applicable to a particular regional context and association, and preclude generalisation to other similar associations based elsewhere in the world.

\section{Research Aim and Methodology}

We have used a historical lens to provide an overview of the history of the Southern African Association for Institutional Research (SAAIR), gathering information through an analysis of documents and conducting a survey.

The themes explored in the study include the organisational paradigm of the SAAIR, the origin and early context of SAAIR, development drivers, leadership and membership, governance and financial management, research and capacity development, networking, benchmarking the performance of the SAAIR, and opportunities for the Association's future. Most of these focus areas were identified primarily from an analysis of various SAAIR documents. The aspects pertaining to benchmarking and opportunities for the Association were included in the survey because of an absence of formal research in these areas.

The document analysis involved analysing and interpreting information in SAAIR minutes, newsletters, reports and the website. For the survey component, a purposive sampling methodology was employed (Palys 2008:697) to target those individuals with knowledge and experience of the organisation at various times over the 23-year period. The sample consisted of past SAAIR presidents and stakeholders from key organisations within and outside South Africa. The questionnaire design was informed by the themes noted above.

The questionnaire was sent via e-mail to 22 individuals from a range of organisations who either were involved in the SAAIR or had experience of the Association through their interactions or engagements. The survey elicited 15 responses resulting in a $68 \%$ response rate. The profile of the respondents and the number of responses are provided in Table 1:

Table 1: Profile of survey respondents

\begin{tabular}{|l|c|}
\multicolumn{1}{|c|}{ Respondent Type } & No \\
\hline SAAIR Presidents & 6 \\
\hline SA Stakeholders (DHET, CHE) & 2 \\
\hline External International Stakeholders (AIR) & 5 \\
\hline Regional Stakeholders (Namibia) & 1 \\
\hline Long-standing SAAIR Participants & 1 \\
\hline Total & $\mathbf{1 5}$ \\
\hline
\end{tabular}

Views of the survey respondents are incorporated in later sections of this chapter. 


\section{SAAIR Organisational Paradigm}

The history of the SAAIR has been marked by contextual factors that influenced its activities and resulted in certain tensions that have shifted from time to time. Throughout its history there have been tensions between the view of the SAAIR as a "voluntary association" or as a "professional association"; and between the SAAIR as an organisation dominated by South African members or one also including institutional researchers from other countries in the Southern African region. Since its inception, the SAAIR has defined itself as a regional organisation (SAAIR Constitution par 1.2 and 1.3), including countries fully or partly south of the equator on the African continent or on islands near its coast.

There has also been a tension between an "academic" approach to institutional research and a more "hands-on" or practical approach, which is not uncommon in similar associations elsewhere in the world (Rice et al. 2011).

The voluntary nature of the Association and its limited membership has constrained the scope of the resources it could mobilise. Until recently, it has been almost entirely dependent on the voluntary engagement of its executive committee and other members to make progress. As a result, the minutes of the SAAIR executive committee meetings show numerous examples of projects and other undertakings that are not carried out, or carried over from one meeting to another with little or no progress. Its executive committee and broader membership should weigh these deficiencies against what the SAAIR has managed to achieve through the voluntary contribution of time and expertise.

A difficulty for the SAAIR has been that some of its members may not necessarily have seen themselves as "institutional researchers". They have worked in a range of differently named units within their universities and may have seen themselves as South African Post-Secondary Education (SAPSE) officers, later as Higher Education Management Information System (HEMIS) officers, Management Information System (MIS) officers or Quality Assurance (QA) officers, rather than institutional researchers.

Although the term "institutional researcher" has become more widely accepted and used over time, it still tends to be used in a limited sense, referring in the main to those staff members who conduct and analyse surveys within their institutions.

In some universities there is a reluctance to use the term "institutional research" in the naming of units because of a concern that this could lead to confusion between this unit and units focussed on the promotion of research activity by academic staff. Some might even say that institutional research is not "real" research.

\section{Origin and Early Context of the SAAIR}

Our document analysis illuminated various aspects of the origin and early context of the SAAIR. Phil Minnaar, the first Chairperson of the SAAIR, traced the origin of the Association back to "a single idea by a single individual". In an article entitled "Early days of the SAAIR recalled", Minnaar (2002:3) wrote: 
In the case of the SAAIR, that individual was Herman Visser. After returning from an AIR Forum in the USA [in 1993] he suggested the idea of a South African AIR... To take Herman's idea further a few people from other institutions were contacted to test the need for such an organisation. The reaction was positive and a steering committee was formed to get the association off the ground.

The first meeting of the steering committee was held on 29 November 1993. The purpose of the steering committee was to do the groundwork for the formation of the South African Association for Institutional Research, which was to take place at a national Forum at some date during 1994. It was decided at the first meeting, however, that the SAAIR should serve the interests of the whole of Southern Africa. The steering committee consisted of Phil Minnaar (University of South Africa), Chair; Herman Visser (University of South Africa), Secretary; Ian McLean (University of Natal); Marié Oosthuizen (University of Pretoria); and Phlip Pretorius (Technikon Witwatersrand). The inaugural Forum of the SAAIR was held on 17-18 November 1994, at University of South Africa (Unisa), Pretoria.

The first executive committee of the SAAIR, elected at the first Annual General Meeting at the inaugural Forum, consisted of Phil Minnaar, Chairperson; Marié Oosthuizen, Secretary; Herman Visser, Treasurer; Johan Bruwer; Mike Phala; and Pieter Vermeulen.

Reflecting on the context in which the SAAIR began, Minnaar (2002:3) wrote:

Institutional research was in a fledgling phase of development at the various institutions of higher education in South Africa. In most cases separate units were not yet established. Institutional managements were not yet fully aware of the importance of a dedicated unit focusing on the delivery of timeous, dependable and relevant management information, and more in-depth institutional research results for planning and decision making. There was no platform or forum where ideas on the methodologies and techniques of information retrieval, data analysis and presentation could be shared and discussed. Contact between institutions in this regard was ad hoc and on an individual basis.

The theme of the first Forum (now called Conference) was "Institutional Research: The state of the art in Southern Africa" in order to showcase, compare and benchmark what was happening in the region at the time. It was decided to host the first Forum at Unisa because of the leading role that it played at the time in the field of institutional research. The Bureau for Management Information at Unisa was not only the first dedicated institutional research unit, but also the largest in the region at the time of the inaugural Forum. Before the founding of the SAAIR, Unisa's Bureau for Management Information had arranged workshops presented by international institutional researchers such as John Muffo and Jim Nichols. It also agreed with AIR to sell some of their printed material. The net proceeds of these workshops were used to provide part of the seed funding for the establishment of the SAAIR. 


\section{Drivers of the SAAIR's Development}

Reviewing the history of SAAIR through an analysis of a range of SAAIR documents makes it possible to discern certain drivers of the Association's activities.

Even though it is an organisation that has grown up alongside South Africa's fledgling democracy, there is no sign of party political issues influencing the SAAIR's course. The profound changes that have, however, taken place in Higher Education in the name of transformation under the democratic government have provided both challenges and opportunities for the SAAIR and for institutional researchers generally.

The driver referred to here is "government steering". Such steering has had many manifestations, including the creation of the Council on Higher Education (CHE) and the introduction of quality assurance under its Higher Education Quality Committee (HEQC) in 2001. It has also led to the merger of institutions and the creation of new institutional types after 2001. Other measures have included the determination of a programme and qualification mix (PQM) for each institution since 2003, the introduction of the new funding formulae in 2004, an increasingly complex planning and reporting regime, and the introduction of a new Higher Education Qualifications Sub-Framework (HEQSF) in 2008 (Republic of South Africa 2008 and 2012).

Another driver for the development of the SAAIR is what may be called "international example". The very idea of creating SAAIR was the result of founder members attending AIR forums in the United States and presenting papers from the late eighties and early nineties, and of ad hoc interactions with international colleagues, mainly from the USA. Many of the initiatives that the SAAIR has successfully undertaken in pursuit of its stated purposes have been modelled on the experiences of members abroad. For example, the use of the term "Forum" for the annual conference and "Institute" for the capacity-development workshops of the SAAIR was adopted from international institutional research associations such as AIR and the Australasian Association for Institutional Research (AAIR). A number of SAAIR initiatives were based on interactions with individuals active in institutional research in other countries and with associations for institutional research based in Australia and Europe.

Another driver that has had an effect on the SAAIR, as it has on virtually all organisations, whether voluntary or not, has been technological change. During the previous two decades the manner in which institutional researchers did their work was constantly affected by technological developments. For example, there has been a shift away from paper-based surveys to electronic surveys, and later to online surveys (despite the poor response rates usually associated with electronic surveys). Institutional research units/departments are nowadays subscribing to a range of survey software tools such as SurveyMonkey and Qualtrics.

\section{SAAIR Leadership}

Throughout its history, the SAAIR has been served by committed and passionate presidents which has enabled the Association to grow from strength to strength. Since its establishment in 1994 the SAAIR has had ten presidents: Phil Minnaar (1994/1995 and 1995/1996), 
Pieter Vermeulen (1996/1997), Ian McLean (1997/1998), Amanda Lourens (1998/1999 and 1999/2000), Cay van der Merwe (2000/2001), David Bleazard (2001/2002 to 2004/2005), Sukude Matoti (2005/2006), Glen Barnes (2006/2007 and 2007/2008), Jan Botha (2008/2009 to 2011/2012), Nicolene Murdoch (2012/2013 to 2015/2016).

While the Executive Committee of the SAAIR has been dominated by South Africans, members from other countries in the Southern African region have made a significant contribution.

The following members served on the Executive Committee: Zach Kazapua (Namibia), Carlos Machili (Mozambique), Daniel Mkude (Tanzania), Onalenna Silas (Botswana), Marsha Cawood (Namibia), Corneels Jafta (Namibia), Elizabeth Ngololo (Namibia) and Kagiso Kobedi (Botswana).

Zach Kazapua (Namibia), Carlos Machili (Mozambique) and Daniel Mkude (Tanzania) made important contributions as invited speakers during the SAAIR Forums in 1997 and 1998. Prof T Tjivijua (Namibia) was one of the keynote speakers at the SAAIR Forum in 2008 in Windhoek, Namibia and Patrick Molutsi (Botswana) was one of the keynote speakers at the SAAIR Forum in 2009 in Port Elizabeth.

Onalenna Silas was the Forum chair for the first Forum outside South Africa - in Gaborone, Botswana in 2006. In 2008, Marsha Cawood was the Forum chair when the annual Form was held in Windhoek, Namibia.

Margaret Baiketsi, under the leadership of Patrick Molutsi, the Director of the Botswana Tertiary Education Council (TEC), organised an institutional research conference in February 2010. The intention was to consider registering institutional research in Botswana as a regional Association of SAAIR. The conference was well attended but unfortunately it transpired that the majority of the delegates were more interested in academic research and educational research than in institutional research. However, the need for professional development became apparent and Molutsi and Baiketsi were subsequently responsible for organising the first professional development institute that was held outside South Africa in May 2012, a combined Quality and Institutional Research Institute, that took place in Gaborone, Botswana.

\section{SAAIR Membership}

Voluntary associations are dependent on continuing membership and the recruitment of new members. The SAAIR casts its net wide in its understanding of the scope of its potential membership. An analysis of the affiliations of its members during the period 1994-2015 indicates the wide range of institutions and geographic regions that were represented. The membership is mainly from South African higher education institutions. It needs to be noted that from the founding of the SAAIR to the late 1990s, the Association had members from a number of countries other than South Africa, namely Mozambique, Namibia, Swaziland, Tanzania and Zambia. In the late 1990s, the SAAIR also had two members from Egypt. Between 1998 and 2003, a few members from Australia and Canada attended the Forum. Subsequently, interest increased in Botswana and Namibia and the SAAIR attracted a few 
members from these countries, but attracting members from other countries in the region has remained difficult. Almost all members of the SAAIR in 2013/14 were from South Africa with $93 \%$ from public higher education institutions. The SAAIR will have to address the geographic distribution of its membership if it is to reach its full potential.

\section{Governance and Financial Management}

The first constitution of the SAAIR was primarily based on the constitution of the Association for Institutional Research (AIR). It was approved at the Inaugural Forum in 1994. The constitution has been amended a number of times, including fairly major revisions led by Gerrie Jacobs in 2010 and Nicolene Murdoch and Herman Visser in 2013. These made provision for more professional governance and management structures. In 2014, changes were made in the structure of the membership fees.

As the SAAIR continued to mature as an Association, it became increasingly important to enhance its governance, management and staff functions. An annual 2-day strategic planning workshop for the SAAIR Executive Committee was instituted in 2010. One of the SAAIR presidents noted the ongoing efforts to "enhance and professionalise the governance and management of the SAAIR". In 2011, the SAAIR administrator/coordinator post was created and Carin Strydom was appointed as the SAAIR's first employee. Before this milestone, administrative support was provided on a part-time basis, firstly by Adri Humphries (1994/1995) who was followed by Stieneke Senekal (1995/1996 to 31 January 2007) and Carin Strydom (1 February 2007 to 31 December 2010).

From the early days of the SAAIR, the financial management of the Association was aimed at providing good services to its membership. The Association was formed with seed funding of R500. Unisa contributed R200 from the proceedings of AIR books sold during workshops presented by John Muffo and Jim Nichols in the early 1990s. The University of Natal contributed R200, and the University of Pretoria, R100. From these humble beginnings, SAAIR has developed into a sustainable Association with sufficient resources to offer a range of annual capacity development events covering the major focus areas of the Association. In our survey, one of the past SAAIR presidents emphasised the need to ensure "the stability of the SAAIR, in particular the financial sustainability."

The funds of SAAIR are clustered into operational funds, short-term investment funds to accommodate cash flow and to deal with fluctuating income, and medium to long-term investment funds for future growth. SAAIR is currently in the process of registering as a notfor-profit association to comply with income tax regulations.

\section{Research and Capacity Development}

In 2002, the SAAIR began to give effect to some of its more ambitious plans in the area of research and capacity building. The growing need of higher education institutions for institutional research at the time meant that efforts were focused on developing a cohort of well-trained and skilled institutional researchers with research, analysis, and writing competencies. 
The issue of student retention featured prominently in higher education discourse at the time, and this led to the establishment of a sub-committee of the SAAIR headed by Amanda Lourens and a commissioned SAAIR project on student retention. The results of this research project were presented during a workshop at the 2003 Forum at the Technikon Free State in Bloemfontein and played a key role in the conceptualisation and refinement of definitions of retention and throughput for higher education that could be used throughout the region.

A conversation began in 2002 between the SAAIR Executive Committee members and representatives of AIR in the United States on possible collaboration between the SAAIR and the AIR to present a series of training workshops for the SAAIR members in Southern African countries. The original concept was for multiple workshops, one per year over a three-year period, to be held in multiple locations across the region. In the AIR funding proposal to the National Science Foundation (NSF) in the United States, the following outcomes were envisioned (Russell 2002:2):

At least 30 SAAIR members should participate in each annual series of workshops; a corps of SAAIR trainers will be developed through a "train-thetrainer" approach; the SAAIR experience in the organization and management of training workshops will be developed; a contribution will be made to enhancing the capacity of Institutional Researchers in the region.

However, this plan of the AIR and the SAAIR to present multiple institutes over a three-year period in different countries had to be amended after the NSF in the United States indicated that it could not commit itself to the project for more than one year (SAAIR 2004a:3).

In an address to the 2003 SAAIR Forum in Bloemfontein, David Bleazard, the SAAIR president at the time, referred to the impending mergers of higher education institutions and noted the increasing demands that the mergers and other factors - the new funding formula, the Higher Education Quality Assurance process, and the programme and qualification mix (PQM) exercise - were placing on the country's institutional researchers. These demands were multiplying against a backdrop of frequently expressed unhappiness on the part of the Department of Education concerning the overall quality of data provided by higher education institutions (Bleazard 2003:1-2).

Bleazard reported that the SAAIR's executive committee had decided to launch two different kinds of training initiatives in 2004, namely, (a) the provision of training opportunities for South African institutional researchers focused on the use of the Higher Education Management Information System (HEMIS) and other submissions required by the Department of Education, and (b) the provision of training opportunities for institutional researchers from other countries in Southern Africa focusing on generic IR skills, such as surveying, data management, reporting, and statistics (Bleazard 2003:2).

These initiatives relate to two key purposes of SAAIR namely, a) "to benefit, assist, and advance institutional research leading to improved understanding, planning and operation of institutions of higher education" (SAAIR Constitution par 2.1), and b) to provide "capacity development and national, regional and international networking opportunities" (SAAIR Constitution par 2.4). 
Following the AIR model of training institutes, the SAAIR decided also to use the term "institute" for its training events (SAAIR 2004b:4). The SAAIR's first HEMIS Institute, on 3-4 May 2004, was based on the international example of AIR and was prompted by the reporting requirements that Higher Education Institutions had to meet in terms of the government's steering instruments. In the invitation to members to attend the Institute, the SAAIR (2004c:1) said that the Institute was "aimed at improving the reporting by South African institutions to the Department of Education by enhancing the skills and confidence of staff members who contribute to the HEMIS submission". The programme outline stated: "The Institute starts from the new Funding Formula, and then takes participants through the various data elements contributing to the institutional submission to the Department of Education" (SAAIR 2004c:1).

The first two Institutional Research Institutes, held at Peninsula Technikon in Cape Town in June 2004, were clearly indebted to the international example of AIR. The theme of the first IR Institute from 15-18 June 2004 was "Developing and Applying Institutional Research Skills within the Context of the Institutional and National Data Needs". The theme of the second IR Institute from 21-24 June 2004 was "Developing and Applying Institutional Research Skills focusing on Academic and Financial Issues".

Since 2004, the SAAIR has continued to present Institutes on institutional research and HEMIS. In 2011, the HEMIS Institute was expanded to include a one-day HEMIS Foundations workshop aimed at novices working in the area of Institutional Research (SAAIR 2011).

The following table shows the number of participants at the SAAIR institutes and workshops since 2010. (The "Regional Workshop" refers to a workshop offered in a particular province or region of South Africa, rather than a workshop for Southern Africa as a region.)

Table 2: Attendance at the SAAIR Institutes and Workshops

\begin{tabular}{|l|c|c|c|c|c|c|}
\hline \multicolumn{1}{|c}{ EVENT } & $\mathbf{2 0 1 0}$ & $\mathbf{2 0 1 1}$ & $\mathbf{2 0 1 2}$ & $\mathbf{2 0 1 3}$ & $\mathbf{2 0 1 4}$ & $\mathbf{2 0 1 5}$ \\
\hline HEMIS Institute & 76 & 72 & 96 & 68 & 84 & 120 \\
\hline HEMIS Institute Foundations Workshop & - & 68 & 56 & 37 & 41 & 78 \\
\hline HEMIS Foundations Regional Workshop & - & 60 & 75 & 32 & 20 & 65 \\
\hline Institutional Research Institute & 20 & $57^{*}$ & 25 & 40 & - & 21 \\
\hline Institutional Research Foundations Workshop & - & - & - & - & - & 20 \\
\hline Quality Assurance Institute & 47 & $57^{*}$ & 67 & 46 & 48 & 38 \\
\hline Learning Analytics Institute & - & - & - & - & - & 53 \\
\hline
\end{tabular}

* Joint Institute (Institutional Research Institute and Quality Assurance Institute) with some plenary sessions and some split sessions.

Based on the number of delegates who attended these events and the mostly positive feedback received from them, it is evident that the SAAIR contributed significantly to the professional development of IR practitioners from the higher education sector in the region. As described in Chapter 5, which deals with professional development for institutional research, the South African Department of Higher Education and Training officially recognises the SAAIR HEMIS Institute as an official stakeholder (Republic of South Africa 2013:21), 
which is an acknowledgement of the contribution made by the SAAIR. It should be noted that, apart from its content, the location and the timing of the event play an important role in determining the number of attendees. For example, in 2013 the University of Venda, which is located in the far north of the country, hosted the HEMIS Institute. Although this made it difficult for some delegates to attend, the SAAIR nevertheless received positive feedback on the content.

In 2010, the SAAIR entered into a contract with AIR to make the AIR Data \& Decisions courses available to the SAAIR members. A first cohort of 17 SAAIR members completed these courses in 2011. A second cohort began in 2015.

In 2006, the SAAIR offered its first Quality Assurance Institute. This was a response by the Association to an important change in the higher education landscape following the introduction of quality assurance by the South African government as the third steering mechanism, along with planning and funding. The National Council for Higher Education (NCHE) in Namibia and the Tertiary Education Council (TEC) in Botswana also introduced national quality assurance systems for higher education. As a result, institutional researchers were required to support quality processes and initiatives within their institutions.

Following the workshop on learning analytics that preceded the 2014 SAAIR conference, the first Institute in learning analytics took place on 17 March 2015. As most higher education institutions are moving toward data-driven decision making and are attempting to improve student success, the institute fulfilled an important need for the basic foundations of learner analytics. The Institute was presented by Victor Borden, a past president of AIR, and was designed for those who were new to the field of learner analytics.

Based on the example of making the wealth of information contained in American Integrated Post-Secondary Education Data System (IPEDS) more widely accessible - the main focus of AIR's Data Policy Institute - the SAAIR took initiatives to make the HEMIS data more widely accessible. The result of these initiatives is that information on all the public universities in South Africa, as audited and submitted to the Department of Higher Education and Training (DHET) via the HEMIS reporting system, is now accessible via the World Wide Web on the Peer Data Sharing (PDS) site maintained by the private company IDSC, based in Potchefstroom, working in close cooperation with the SAAIR.

\section{Networking}

From its early days, the SAAIR has been keen to maintain international linkages. For the inaugural Forum, three international keynote speakers were invited, namely, Hans Acherman (from the Netherlands and Chair of the International AIR Committee), Neil Bardsley (from the Australasian Association for Institutional Research, AAIR) and John Muffo (from AIR).

As a result of its interactions with international colleagues, the SAAIR was included in the AIR, the AAIR and the EAIR (the European Association for Institutional Research) cooperation agreement. This agreement was under the auspices of AIR's International Committee, which was chaired by Hans Acherman. The SAAIR was added to the agreement in 1995 . This made provision for various forms of collaboration, for example, for members of the 
different Associations to attend each other's Forums and to become members of the other Associations at reduced rates if they were paid-up members of their local Association. The agreement lapsed after the term ended when the External Relations Committee superseded the International Committee in 1998 after Hans Acherman's retirement.

Nevertheless, fostering international relationships continued in a mutually reciprocal manner. Respondents commented in particular on the relationship between the SAAIR and the AIR members who were represented at each other's Forums ("International colleagues were invited to the SAAIR Forum and the SAAIR was represented at the 1999 AIR Forum in Seattle where valuable contacts were established") and one SAAIR respondent also networked with the CEO of AIR ("I visited the AIR Office in Tallahassee in 2009 and established links with AIR's CEO, Randy Swing as well as AIR staff members").

The high priority given by the SAAIR to international cooperation and to raise awareness of the activities of the Association locally and in other countries is evident from the following comments by our respondents:

"Expanding regional awareness of the SAAIR. Valuable input was provided at various strategic platforms - including the Eastern Cape Council for Higher Education Associations (ECCHEA) and ICOTS (International Conference on Teaching Statistics) whereby a workshop had been offered prior to the 2002 ICOTS conference."

"The activities of the SAAIR were published in internal publications of institutions."

SAAIR has worked hard to establish and maintain good networks with national entities such as the Department of Higher Education and Training (DHET) in South Africa, the Council on Higher Education (CHE) in South Africa, the Department of Planning, Monitoring and Evaluation (DPME) in South Africa, and the Tertiary Education Council (TEC) in Botswana. The SAAIR's networking with DHET was positively acknowledged by a national stakeholder who commented that it "improved the quality of data submissions from universities to the DHET".

SAAIR's various networking activities garnered favourable comments from international and regional stakeholders. According to a regional stakeholder who served on the SAAIR Executive Committee in 2012, the collegial relationship between the Polytechnic of Namibia (since 2015 known as the Namibia University for Science and Technology) and the SAAIR can be credited with the establishment of the Polytechnic's Management Information and Institutional Research Unit (MIIR). This was achieved through the capacity development initiatives and activities of the SAAIR that empowered staff with knowledge and skills. The following comment captures the sentiments of this stakeholder on the role of the SAAIR in the region:

"The best part of it all is that the SAAIR imparts this knowledge through the collegial sharing of knowledge, which is a tremendous benefit to institutions, especially those in the SADC region." 
A common thread in the responses from international stakeholders about the achievements of the SAAIR was that it provided a professional network and learning opportunity for its practitioners both locally and internationally, and, as a consequence, provided the SAAIR with a national and international identity in its service to the broader spectrum of higher education professionals beyond its membership. This is reflected in the following responses from our respondents:

"Providing an international identity for members is definitely an achievement. For example, the first time I met the SAAIR members was at EAIR in 2002 (Prague), followed by the AIR Forum in Kansas City in 2006. The SAAIR also provides national identity for institutional research and higher education in South Africa."

"Providing a professional network for institutional researchers and other professionals provides a mechanism for setting standards and expectations for the level of quality and rigor."

SAAIR's role in providing a platform for the "sharing of ideas, practices and challenges" is regarded as another achievement by international stakeholders. An international stakeholder acknowledges the high standard of institutional research practice in South Africa:

"I have always been positively impressed with the level of sophistication among South African IR practitioners."

International stakeholders also commented on the concerted effort by the SAAIR to regionalise institutional research, particularly its role in serving as an "umbrella organisation for individuals from Zimbabwe, Botswana and Namibia."

\section{Benchmarking the Performance of the SAAIR}

Given that the SAAIR is relatively young in comparison with its international peer associations, a benchmarking component was included in the survey to elicit perceptions of how the SAAIR fares relative to other similar Associations. The following statement was made and respondents were requested to indicate their response on a five point scale: the SAAIR has to make significant improvements to reach the same level of performance in comparison to similar international organisations. The distribution of responses for the different categories of participants is presented in the table below.

Table 3: Benchmarking the SAAIR

\begin{tabular}{|l|c|c|c|}
\multicolumn{1}{|c}{ Response category } & SAAIR presidents (6) & $\begin{array}{c}\text { South African } \\
\text { and regional } \\
\text { stakeholders, and } \\
\text { SAAIR participants (4) }\end{array}$ & $\begin{array}{c}\text { International } \\
\text { stakeholders (5) }\end{array}$ \\
\hline Strongly disagree & - & - & 1 \\
\hline Disagree & 3 & 2 & 1 \\
\hline Neither agree nor disagree & - & 2 & 3 \\
\hline Agree & 3 & - & - \\
\hline Strongly agree & - & - & - \\
\hline
\end{tabular}


Of the six SAAIR presidents who responded, three disagreed with this statement while three agreed. Some explanations from those that disagreed that the SAAIR has to make significant improvements to reach the same level of performance as other similar international organisations focused on the success of the SAAIR events ("I have attended many similar functions in other countries, I think we offer an equal experience to those and I think we arrange very successful events") and noted that important changes had taken place across Associations ("AIR and EAIR have improved drastically during recent years, much much improved, we (SAAIR) did not change that much, although there were important changes"). While disagreeing that the SAAIR has to make significant improvements to reach the same level of performance as other similar international organisations, one respondent highlighted the challenge of a limited audience for institutional research in Southern Africa ("our challenge will be in further participation in an area with an already limited audience in Southern Africa").

The three presidents who agreed that the SAAIR has to make significant improvements to reach the same level of performance as its peer organisations, focused on the absence of a scholarly journal as a barrier ("The only reason I agree with the statement is in relation to research publications and studies done by members (in international organisations) and published in accredited journals (which we do not have). For example, consider the 'New directions of IR' publication by AIR and other publications by AIR"), limited membership ("the scale of the SAAIR's membership is a restraining factor"), and having to keep up with international developments ("SAAIR certainly has to improve, but that does not mean it has to struggle as if it has not been doing anything. The SAAIR started in 1994 and at that time much had already been going on in the international front. It has to keep up with international developments").

A regional stakeholder responded positively about the performance of the SAAIR's relative to its peers:

"My experience is that the SAAIR has performed well, on a comparable level with other such organisations."

The response from a long-standing SAAIR participant focussed on the Association's good comparative performance relative to its age and noted that there was room for improvement, as follows:

"After attending many AIR and EAIR conferences, I came to the conclusion that the SAAIR can be proud of its performance over the years, especially since it is still a relatively young Association. This, however, does not mean that no improvement is necessary."

Of the five international stakeholders who participated in the survey and responded to this question, one strongly disagreed with the statement and two others disagreed. The explanations included the view that the SAAIR has the critical human capacity to make notable progress ("I disagreed because I believe the critical human elements are already present for the SAAIR to make significant progress") while at the same time highlighting the importance of a centralised structure for the SAAIR in the future and the benefits thereof 
("what might be lacking is a centralized staff that could relieve some of the day-to-day burden of serving not just its membership but organizing workshops and other learning opportunities. That would be a direction that could be pursued, and would make the SAAIR a much different organization if the membership decided to raise its dues, look for funding opportunities, and centralise"). The respondent in question provided concrete examples of organisations that benefitted from a centralised structure ("according to my reckoning there are two AIR organisations that benefit from a centralized structure, the mothership (AIR in Tallahassee) and EAIR in the Netherlands"), and the additional activities this has enabled ("both are significantly larger (than the SAAIR) and the AIR has built alternate funding streams through government contracts. These contracts have a downside, however, since they require work that isn't directly a member service. The upside is that they provide national visibility").

Other respondents who disagreed with the statement indicated that the SAAIR was performing at a reasonable level given its context ("From my limited exposure, the SAAIR seems to be performing at a reasonable level, especially given its context (that is, general resources available)". They positioned the SAAIR favourably relative to its peers ("the SAAIR is right up there with the other high level international IR associations outside the U.S. including Canada, Europe, and Australasia") and also noted the level of sophistication of the SAAIR ("I think they are more advanced than others at this time").

Finally, there were two international stakeholders who were non-committal. Their explanations do, however, acknowledge the international activity of members of the SAAIR as well as the strength of their skills and abilities ("the SAAIR is a vibrant organization and your members are active not only in Southern Africa, but often present papers and seminars at other institutional research meetings internationally. My experience has been that these presentations reflect strong research and presentation skills. This is important if the SAAIR is to maintain its presence in the international IR community"). Furthermore, useful suggestions were provided about enhancing scholarship through publications to strengthen the presence of the SAAIR in the international IR community ("I would argue that to strengthen that presence would involve enhancing the scholarship aspect of the SAAIR's activities by publishing books and/or a paper series like AIR's Professional File and the monograph series (see the AIR website) and making them available to all wanting to study related aspects of IR and planning"), with the view that the scholarship should be globally relevant ("while this scholarship might have a South African reference, its message should be relevant to institutional research globally").

One international respondent who was non-committal felt that his contact with the SAAIR was insufficient to warrant a knowledgeable response to the statement, but felt that based on his experience of when things first started, some members of the SAAIR had knowledge and skills which were of an international standard while this was less so for others ("I have not had enough contact with the organization in recent years to offer an informed response to this question. My experience was in the beginning when things were first getting started. At that time there were members who were at an international standard of knowledge and skill and others who were not quite as strong, but there is also a range within other organizations internationally. I'm not sure what the situation is today"). 
It is noteworthy that none of the international stakeholders was of the opinion that the SAAIR has to make significant improvements to reach the same level of performance in comparison to similar international organisations.

\section{Opportunities for the Future Development of the SAAIR}

The SAAIR presidents and stakeholders in the survey component of the study suggested various opportunities for the future development of the Association.

A very specific opportunity in relation to the use of higher education institutional data was to enhance the importance of the collection of accurate higher education institutional information (e.g. HEMIS) and the analysis of the collected data, in order to compare and benchmark the performance of universities effectively.

Another opportunity for the SAAIR involves obtaining a more comprehensive view of the higher education sector through structures such as the Higher Education Quality Committee Information System (HEQCIS) and UNESCO's Institute for Statistics (UIS) that collects data on education from various countries. Interacting more closely with the Southern African Regional Universities Association (SARUA) was mentioned as an opportunity to assist in the development of data collection in Southern Africa. This will provide a more comprehensive view of higher education in the region.

Other networking activities both within and outside the SAAIR featured strongly as an opportunity suggested by our respondents, for example, creating "stronger connections and communications among the SAAIR members, other SA region colleagues and international colleagues in IR and related professions", and increasing the "synergy" between the Higher Education Learning and Teaching Association of South Africa (HELTASA) and the SAAIR.

Some respondents saw an opportunity for broadening the scope and contribution of IR at the sectoral level which includes being proactive in providing key responses to government or other agencies/organisations. According to one international stakeholder, this included forging trustworthy relationships between business, government and universities with the aim of having "short and intermediate programmes that result in learning communities". Other respondents suggested strengthening the voice of the SAAIR in the sector, including having the SAAIR proactively respond to national policy initiatives. It could forge closer working relationships with key organisations such as the National Research Foundation (NRF), the Human Sciences Research Council (HSRC) and the Department of Science and Technology (DST) in relation to their work, and undertake research to solve some of the problems facing the region. Some of these suggestions are captured in the following responses:

"One aspect would be to provide the SAAIR research responses/reports on policy matters and/or to work more closely with organisations such as Universities South Africa (the former HESA) and the Centre for Higher Education Trust (CHET) in relation to the studies that they undertake with relevance to the SAAIR objectives. This would strengthen the voice of the SAAIR." 
"Higher education in South Africa is facing difficult and sometimes unique problems and challenges. The SAAIR should identify these areas and endeavour to proactively identify and take on research in areas that can contribute towards solutions to some of these problems."

Collaborating with other countries facing similar higher education challenges is seen to be an opportunity to bring "not just visibility (to the challenges facing SA) but mutual improvements in practice". One stakeholder echoed these sentiments:

"If we share what works and doesn't work, that will be a great advance. The

SAAIR must be part of that conversation to be relevant, viable and sustainable."

The provision of qualitative data is regarded as an opportunity to move beyond simply providing decision-makers with quantitative data. For example, initiatives can be considered by the SAAIR to provide capacity building and professional development opportunities to various units within institutions (for example, planning and QA), by "helping them link functional-level data to strategic decision-making".

A somewhat novel opportunity suggested by one respondent is that of developing new types of data for the Southern African context that would involve the SAAIR and its members using the tools and techniques of North America and Europe, while at the same time providing insights into the "demographically shifting societies that are served by SA universities".

Some of our respondents saw an opportunity for enhancing awareness about the value of IR among members of university management structures through networking, which would involve "making solid connections with the groups and associations that support the administrative leaders, so that the good word about the value of IR as a professional network can spread to those to whom IR practitioners report". This also involves elevating the contribution and subsequent reputation of IR to support university leadership effectively by making data-based information "relevant for informed and knowledgeable decisionmaking". This will make the IR professional a "critical component of the institution's leadership". One stakeholder captured this sentiment eloquently:

"The professionalisation of IR practice was regarded as a critical opportunity by some respondents for ensuring the longer term stability and viability of the Association and for ensuring a "higher level of service to members". One stakeholder felt that universities should take the lead in developing postgraduate qualifications for people interested in pursuing institutional research as a career.

Other respondents saw opportunities for securing donor funding, extending the role of the central office of the SAAIR, establishing a presence in other Southern African countries to improve the regional footprint and enhancing the quality of the SAAIR conferences, the latter through continuing to attract recognised and reputable speakers to events and ensuring that the programme is of a high quality through effective peer review.

Finally, initiatives related to proper curriculum development for the SAAIR Institutes and participating actively in the new initiatives related to Learning Analytics are considered to be important opportunities for the Association. 


\section{Conclusion}

This study has shed light on the history of the SAAIR as a voluntary association. In doing so, it has foregrounded the development of institutional research as a profession within the Southern African higher education context. The various initiatives for developing capacity, including the SAAIR Institutes and workshops, have underscored efforts to develop IR as a profession. The need for a formal qualification in IR has also been raised.

The study provides an opportunity of understanding the history of the SAAIR and of using this to shape and influence the future direction and contribution of the SAAIR. The findings of the study have implications for the improvement of the Association and provide useful insights into how it can remain relevant, effective and valuable. It draws attention to various opportunities for growth and expansion of the Association and the profession of IR.

SAAIR needs to champion change proactively and to lead efforts to expand the profession of IR within higher education institutions in the Southern African context. This will contribute to the sustainability of IR as a profession dedicated to providing decision support in higher education. It goes without saying that the SAAIR should continually strive to ensure that IR is recognised as an asset to planners and decision makers within higher education institutions.

\section{References}

Badat, S. 2010. The Challenges of Transformation in Higher Education and Training Institutions in South Africa. Pretoria: Development Bank of South Africa.

Bleazard, D.K. 2003. SAAIR Forum 2003: Chairperson's Address.

Calderon, A.J. \& Webber, K.L. 2015. Institutional research, planning and decision support in Higher Education today, in A.J. Calderon \& K.L. Webber (eds.). Institutional Research and Planning in Higher Education: Global Contexts and Themes. Routledge. 4-15.

Department of Higher Education and Training. 2013. White Paper on PostSecondary Education and Training: Building an Expanded Effective and Integrated Post-School System, as approved by Cabinet on 20 November 2013. Pretoria: Department of Higher Education and Training.

Kotecha, P. (exec. ed.), Wilson-Strydom, M. \& Fongwa, S.N. 2012. A Profile of Higher Education in Southern Africa - Volume 1: A Regional Perspective. Johannesburg: Southern African Regional Universities Association (SARUA). 1-82.
Ministry of Education. 2001. National Plan for Higher Education. Pretoria: Department of Education.

Minnaar, P.C. 2002. Early days of the SAAIR recalled. SAAIR Newsletter 4(2), November 2012. 3.

National Council for Higher Education. 2009. Quality Assurance System for Higher Education in Namibia. Windhoek: National Council for Higher Education (NCHE).

National Council for Higher Education. 2010. The Quest for Coordination of the Higher Education System in Namibia. Windhoek: National Council for Higher Education (NCHE).

National Planning Commission. 2011. The National Development Plan 2030.

Pretoria: National Planning Commission.

Palys, T. 2008. Purposive Sampling in L.M. Given (ed.). The Sage Encyclopaedia of Qualitative Research Methods, Vol. 2. Los Angeles: Sage. 697-698.

Patton, M.Q. 1980. Qualitative Evaluation and Research Methods (2nd Ed). California: Sage.

Reichard, D.J. 2012. The History of Institutional Research in R.D. Howard, 
G.W. McLaughlin \& W.E. Knight (eds.). The Handbook of Institutional Research. San Francisco. 3-22.

Republic of South Africa. 1997. Higher Education Act 101 of 1997. Pretoria: Government Printer.

Republic of South Africa. 1997a. Education White Paper 3: A Programme for the Transformation of Higher Education. Government Gazette No. 18207, 15 August 1997. Pretoria: Government Printer.

Republic of South Africa. 2008. National Qualifications Framework Act, Act No. 67 of 2008. Government Gazette No. 31909. Pretoria: Government Printer.

Republic of South Africa. 2012. The Higher Education Qualifications SubFramework, as revised. Government Gazette No. 36003, 14 December 2012. Pretoria: Government Printer.

Republic of South Africa. 2013. Higher Education and Training Information Policy. Government Gazette No. 36973. Pretoria: Government Printer.

Rice, G., Coughlin, M.A. \& Howard, R. 2011. The Association for Institutional Research: The First 50 Years. Florida: AIR.

Russell, T. 2002. Draft Preliminary Proposal from the Association for Institutional Research in cooperation with the
Southern African Association for Institutional Research: Improving Skills and Capabilities in the Conduct of Institutional Research in Southern African Postsecondary Educational Institutions. (12/10/02).

SAAIR. 1994. Constitution of the Southern African Association for Institutional Research (SAAIR), as amended. Available at http://www.saair-web.co.za/.

SAAIR. 2004a. Minutes of a meeting of the Executive Committee of the Southern Africa Association for Institutional Research (SAAIR) on 19 April 2004.

SAAIR. 2004b. Minutes of a meeting of the Executive Committee of the Southern African Association for Institutional Research (SAAIR) on 24 January 2004.

SAAIR. 2004c. SAAIR: HEMIS Institute. (Undated invitation).

SAAIR. 2011. Minutes of a meeting of the Executive Committee of the Southern African Association for Institutional Research (SAAIR) on 3 March 2011.

Seaman, J.T. \& Smith, G.D. 2012. Your Company's History as a Leadership Tool. Harvard Business Review, December. 1-6.

Tertiary Education Council Botswana (TEC). 2010. Strategic Plan 2010-2012/2016. Gaborone: Tertiary Education Council. 